\title{
Partially-Saturated Transient Groundwater Flow Model Theory and Numerical Implementation
}

1975

This report is based on work sponsored by the Atlantic Richfield Hanford Company under United States Energy Research and Development Administration Contract AT(45-1)-2130 
NOTICE

This report was prepared as an account of work sponsored by the United States Government. Neither the United States nor the Energy Research and Development Administration, nor any of their employees, nor any of their contractors, subcontractors, or their employees, makes any warranty, express or implied, or assumes any legal liability or responsibility for the accuracy, completeness or usefulness of any imformation, apparatus, product or process disclosed, or represents that its use would not intringe privately owned rights.

\author{
PACIFIC NORTHWEST LABORATORY \\ operated by \\ BATTELLE \\ for the \\ ENERGY RESEARCH AND DEVELOPMENT ADMINISTRATION \\ Under Contract E(45-1)-1830
}

Printed in the United States of America

Available from

National Technical Information Service

U.S. Department of Commerce

5285 Port Royal Road

Springfield, Virginia 22151

Price: Printed Copy \$5.50; Microfiche \$2.25 


\section{9}

\section{PARTIALLY-SATURATED TRANSIENT GROUNDWATER FLOW MODEL THEORY AND NUMERICAL IMPLEMENTATION}

BY

A. E. Reisenauer

D. B. Cearlock

C. A. Bryan*

Appendix by

Gaylon S. Campbell**

Water and Land Resources Department *University of Montana, Missoula, Montana **Washington State University, Pullman, Washington

\section{5}

This report is based on work sponsored by the Atlantic Richfield Hanford Company under United States Energy Research and Development Administration Contract AT $(45-1)-2130$

BATTELLE

PACIFIC NORTHWEST LABORATORIES

RICFILAND, WASHINGTON 99352 
This report describes the mathematical development of a computer model, the Partially-Saturated Transient Flow Model (PST), used to test the formulation for simulating isothermal, unsaturated, liquid flow in heterogeneous porous media. The fundamental equations and assumptions applying to the model are discussed. Problems encountered in modeling the flow in soils with water contents less than saturation are also delineated.

Because of the nonlinearities of the descriptive equations, finite difference approximation and an iterative technique were used to obtain solutions. The model, when tested, was computationally slow and impractical as a management tool but did demonstrate that the equation could be solved for flow entering relatively dry soils.

Several methods of dealing with the sediment hydraulic characteristics were tested. 


\section{CONTENTS}

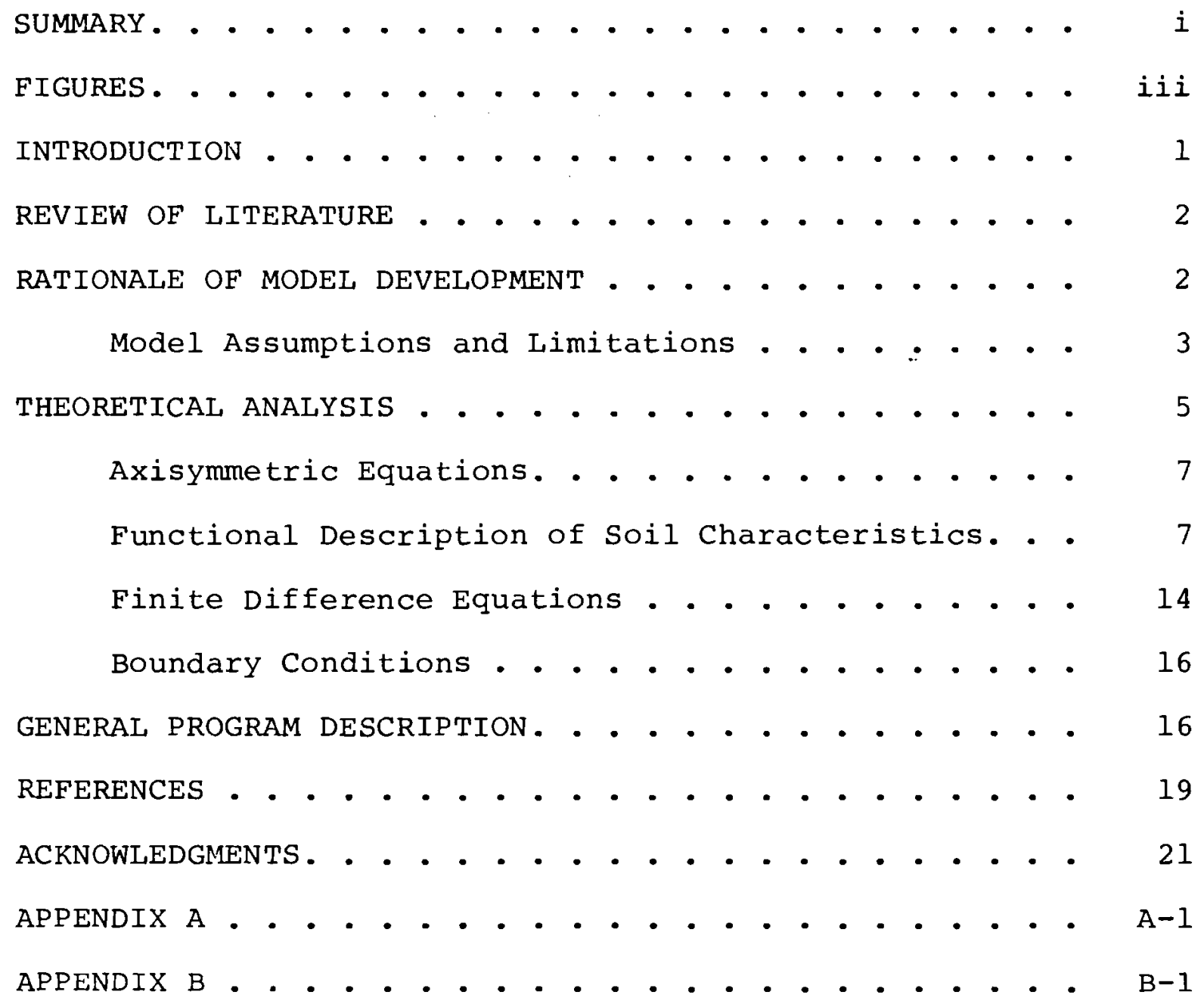




\section{FIGURES}

1 Relative Permeability Versus Capillary Pressure Curve and the Functional Fitting Equation . . . . . . . . . . . . .

2 Capillary Pressure Versus Saturation Curves and the Functional Fitting Equation

3 Hydraulic Conductivity Versus Suction Head for the "A" Tank Farm Soil. . . . . . . . .

4 Water Content Versus Suction Head for the "A" Tank Farm Soil . . . . . . . . . . . . . .

5 Points used in Time and space for Crank-Nicolson Finite Difference Expression. . . . 14

6 Schematic Showing Shapes and Rotation of Available Boundary Nodes . . . . . . . . . . . 


\author{
PARTIALLY-SATURATED TRAINSIENT GROUNDWATER FLOW MODEL \\ THEORY AND NUMERICAL IMPLEMENTATION
}

\author{
INTRODUCTION
}

At the Hanford Reservation, radioactive wastes are presently stored in the ground in unsaturated (or partially-saturated) sediments lying between 45 and 60 meters above the regional water table. Since many of the long-lived radiocontaminants are readily adsorbed on the sediments and since water movement at the moisture content found in the Hanford sediments is slow, this zone has been theoretically relied upon, in the event of a storage tank leak, as a safety factor to minimize possibility of radiocontaminants entering the water table. Thus, the ability to quantitatively calculate radiocontaminant movement in this zone is extremely important to waste management activities at Hanford.

An effort was initiated to quantitatively describe radiocontaminant movement in the vadose zone (the zone between the ground surface and the water table). To quantitatively describe radiocontaminant movement in the vadose zone, it is necessary to solve the equations for water movement and solute transport. If it is assumed that flow of water is independent of the water's chemical constituents (i.e., that the important forces governing fluid movement are physical), then the equations for fluid and mass flow can be solved sequentially rather than simultaneously, thus greatly reducing the problem of obtaining numerical solutions.

The PST Model was designed to predict the moisture movement in sediments as a function of time and space for the initial and boundary conditions, which are specified. Once a solution to the flow problem is obtained, a transport model can be used to combine the moisture movement rates with soilwaste reaction mechanisms to predict the time and spatial movement of important radiocontaminants. This report describes the theory and numerical implementation of the PST Model. 
The infiltration of water through sediments is characteristically a two-phase flow problem, the water either replacing or being replaced by air. Since there is small resistance to flow of air, it is assumed that for isothermal conditions the problem can be reduced to the flow of the liquid phase; i.e., that of the water. Corey (1) suggested that air pressure in such a case is usually atmospheric.

These assumptions were used by Richards (2) in combining the equation of continuity and Darcy's Law to develop the generally accepted equation describing flow in a porous medium. This is a nonlinear parabolic partial differential equation in which the coefficients are a function of the dependent variable. Such equations are difficult to solve with the usual numerical techniques. One-dimensional numerical formulations of Richards' equation were reviewed by Freeze. (3) Recently, two-dimensional applications were published by Rubin, (4) Hornberger, et al., (5) Taylor and Luthin, (6) Cooley, (7) Verma and Brutsaert, (8) and Brutsaert. (9) Green and Weinaug (10) published a two-phase, two-dimensional solution but also encountered excessive computational times. Freeze(11) published a three-dimensional model that treated the entire (saturated-unsaturated transient) flow of a small geologic basin. With the exception of Freeze and Brutsaert, all of these authors used homogeneous soils. The sharp discontinuities arising from sudden application of water to relatively dry soils have not been treated.

\section{RATIONALE OF MODEL DEVELOPMENT}

The most general equations that describe liquid, vapor, heat and solute flow through unsaturated sediments are very complex. The equations for liquid and vapor movement (treated by Taylor and Cary, (12) Philip and Devries, (13) and Letey (14) have not yet been solved for the general case.

In making simplifying assumptions, consideration should be given to the economic feasibility of solving the resultant equations, the cost of obtaining the necessary input data, and the status of the theory describing the effect. For instance, it is known that highly saline wastes can react with the sediments to change their hydraulic characteristics; however, the theory has not been developed to describe this reaction, as it must be before this effect is properly included in a model. 
Because of the above mentioned considerations and the nonlinearities associated with solving even the simplified isothermal equations for waste storage tank leaks or pipeline ruptures in relatively dry heterogeneous sediments, it was decided that the first step in the development of the PST Model would be to solve the isothermal equations for the hydrogeologic and climatic conditions which prevail at the Hanford Reservation. The experience gained in solving these equations could contribute to better decisions about the feasibility and desirability of modeling other effects.

\section{MODEL ASSUMPTIONS AND LIMITATIONS}

The following assumptions, which are discussed below, were made for model development:

1) Darcy's law is generally accepted as valid for types of sediments and gradients that occur in the vadose zone of the Hanford Reservation. This is a generally accepted assumption used in development of equation of flow through porous media. In partially saturated flow the hydraulic conductivity is dependent upon the moisture content.

2) The pressure head is a unique function of the volumetric moisture content. This is to say that hysteresis is ignored. Richards (16) found that drainage was faster than wetting as the capillary pressure varied between the same values, which could be accounted for by hysteresis. For the same pressure variations, the difference in moisture contents were largest (up to 10 percent) for heavy clay soils, smallest for coarse sands ( 1 to 2 percent). Defining the hysteresis loops adequately presents an order of magnitude more difficult measurement problems and probably represent less error than that of using disturbed sediment samples for measuring hydraulic characteristics.

3) In addition, more recent work by Dane, (17) indicates that hysteresis is a second order effect when consideration is given to the accuracy with which the hydraulic conductivity can be established. The soil may be homogeneous or homogeneously layered. In the case of a two-dimensional problem the sediment layers can be either horizontal or tilted. In an axisymmetric problem the layers must be horizontal or they will appear conical in the three-dimensional view. 
4) The pressure of the air is constant and uniform throughout the system and is used as the datum for measuring the pressure in the wetting phase. It is assumed there is no resistance to the flow of air in the system, therefore, only the wetting fluid needs to be modeled.

5) The soil medium is isotropic within the unit cell. Generally the Hanford sediments are isotropic; however, layering causes an apparent anisotropy.

6) The flow is isothermal. Moisture movement from waste discharges are not significantly affected by the normal earth thermal gradients. Therefore, the isothermal assumption will be valid for most applications. Thermally-induced liquid flow and vapor phase flow can arise from three sources: a) heat content of the waste: b) concentration of radiocontaminants on the sediments through sorption reactions and subsequent radiant heating of the 1iquid; and c) ratural thermal gradients.

Some insight into the importance of the nonisothermal flow at low moisture content induced by natural geothermal gradients can be obtained by using techniques described in Appendix A. The equations therein are based on classical nonisothermal transport theory.

7) The hydraulic conductivity is a unique function of the moisture content.

8) Neglecting overburden is often considered an assumption in the basic equations; however, the effect of overburden is to modify the sediment matrix by increasing the bulk density which in turn changes the hydraulic characteristics of the sediments. Thus, overburden affects the input soil characteristics rather than the basic equations and can be approximately accounted for in measurement of the properties at the same bulk density as occurs in the field.

9) Barometric pressure changes are not accounted for. It is unlikely that liquid under leak conditions is moved by barometric changes.

10) The hydraulic characteristics of the sediments are not altered by the chemical composition of the waste. It has been observed that chemical wastes can react with the sediments and change their hydraulic characteristics, (15) but the specific reactions which occur and 
their significance with respect to liquid and radiocontaminant movement are not known. The assumption that the hydraulic characteristics of the soil are not changed by chemicals in the waste allows the equations for fluid and mass flow to be solved sequentially, rather than simultaneously, which reduces the difficulty of obtaining numerical solutions. A significant development effort would be necessary to incorporate the effects of chemically-caused changes in hydraulic characteristics.

\section{THEORETICAL ANALYSIS}

A set of equations describing nonisothermal liquid, vapor, heat and solute flow in unsaturated sediments is presented in Appendix A. These equations incorporate the important effects which have been suggested in the literature and are presented to show the complexity of the general equations which would have to be solved if no simplifying assumptions were made. It is obvious that solving these equations for a realistically sized problem would be an impractical effort for the present state-of-the-art in numerical analysis and digital computers. The assumptions presented in the previous section were used to reduce these equations to those used in the PST Model. This development is also described in Appendix A.

The generalized equation describing isothermal, incompressible flow in porous media in two dimensions is:

$$
\frac{\partial\left(K \frac{\partial \Phi}{\partial x}\right)}{\partial x}+\frac{\partial\left(K \frac{\partial \Phi}{\partial z}\right)}{\partial z}=\frac{\partial \Theta}{\partial t}-q
$$

where

$$
\begin{aligned}
\Phi & =\underline{\mathbf{P}}+\mathbf{z}=\text { hydraulic potentials } \\
\theta & =\text { moisture content } \\
\mathbf{K} & =\text { hydraulic conductivity } \\
\mathbf{x}, \mathbf{z} & =\text { spatial coordinates } \\
\mathbf{t} & =\text { time } \\
\mathbf{q} & =\text { source or sink term }
\end{aligned}
$$


When saturated flow exists or $\theta=\theta_{s^{\prime}}$ then

where $\underline{P}=P / \rho g$

$$
\begin{aligned}
& \mathrm{P}=\text { pressure } \\
& \rho=\text { density of water } \\
& \mathrm{g}=\text { gravitational acceleration }
\end{aligned}
$$

In this case $\Phi$ and $K$ are functions only of the spatial coordinates, $\mathbf{x}$ and $z$.

When unsaturated flow exists or $\theta<{ }^{\circ} \mathrm{s}^{\prime}$

$$
\underline{\mathrm{P}}=\underline{\mathrm{P}}_{\mathrm{C}}
$$

where $\underline{\mathrm{P}}_{\mathrm{C}}=$ capillary pressure.

In this case $\Phi, K$ and $\theta$ are all functions of the spatial coordinates and the capillary pressure or:

$$
\begin{aligned}
& K=f_{1}\left(x, z, P_{c}\right) \\
& \theta=f_{2}\left(x, z, P_{c}\right) \\
& \Phi=f_{3}\left(x, z, P_{c}\right)
\end{aligned}
$$

It is these relationships which make Equation 1 nonlinear and extremely difficult to solve for large problems with sizable variations in hydraulic conductivities and moisture contents.

The capillary pressure is defined as:

$$
\underline{\mathrm{P}}_{\mathrm{C}}=\underline{\mathrm{P}}_{\mathrm{nW}} \quad \underline{\mathrm{P}}_{\mathrm{W}}
$$

or the difference in pressure in the nonwetting fluid, $\mathrm{P}_{n w^{\prime}}$ and the pressure in the wetting fluid, $P$. If the air $\mathrm{NW}^{\circ}$
pressure is taken as a datum for measuring the pressure of the wetting fluid (i.e., $\mathrm{P}_{n \mathrm{w}}=0$ ), then:

$$
\underline{\mathrm{P}}_{\mathrm{C}}=\underline{\mathrm{P}}_{\mathrm{W}}
$$


Rewriting the right side of Equation 1 using the chain rule gives:

$$
\frac{\partial}{\partial x}\left(K \frac{\partial \Phi}{\partial x}\right)+\frac{\partial}{\partial z}\left(K \frac{\partial \Phi}{\partial z}\right)=\frac{\partial \theta}{\partial \Phi} \frac{\partial \Phi}{\partial t}-q
$$

which is more easily used for the basic differential equation of the model.

\section{AXISYMMETRIC EQUATIONS}

The axisymmetric partial differential equation form of Equation 2 is:

$$
\frac{1}{r} \frac{\partial}{\partial r}\left(K r \frac{\partial \phi}{\partial r}\right)+\frac{\partial}{\partial z}\left(K \frac{\partial \phi}{\partial z}\right)=\frac{\partial \theta}{\partial \phi} \frac{\partial \phi}{\partial t}-q
$$

where $r$ is the radial distance from the axis of symmetry. Multiplying by $r$ and defining:

$$
\overline{\mathrm{K}}=\mathrm{Kr}, \mathrm{U}=\mathrm{r} \frac{\partial \theta}{\partial \phi} \text { and } \hat{\mathrm{q}}=\mathrm{qr}
$$

transforms Equation 3 into a form similar to Equation 2. Hence the same computer routine may be used for both problems with slight revision to take care of the redefinition.

\section{FUNCTIONAL DESCRIPTION OF SOIL CHARACTERISTICS}

ivumerical solutions depend entirely on the functional relationships of $R$ and $\theta$ to capillary pressure. These functional relationships are the hydraulic characteristics of the soil.

The dependence of the hydraulic conductivity on capillary pressure is usually determined in a dynamic flow system or calculated from steady-state measurements. $(18,19,20,21,22)$

Many empirical expressions have been used to describe hyaraulic conductivity as a function of capillary pressure. Several have been used in this model and their limitations are discussed. One equation which relates relative hydraulic conductivity to capillary pressure, known as Gardner's equation, as modified by King, (22) has the form:

$$
\mathrm{K}_{r}=\frac{1}{\left(\frac{\mathrm{C}}{\mathrm{P}_{1}}\right)^{\tau}+b}
$$


where

$$
\begin{aligned}
& \mathrm{K}_{r} \text { is the relative hydraulic conductivity } \\
& \mathrm{P}_{C} \text { is the capillary pressure } \\
& \mathrm{P}_{{ }^{\prime}} \text { ' } \mathrm{T}_{\text {, }} \text { and b curve fitting techniques }
\end{aligned}
$$

Data and fitted curves for three soils are shown in Figure 1 .

In order to solve the basic Equation 2 one other functional relation is required. An equation for the moisture content as a function of the capillary pressure, proposed by King (21) is:

$$
\theta=\delta f\left[\frac{\cosh \left[\left(\frac{P_{C}}{P_{o}}\right)^{\beta}+\varepsilon\right]-\gamma}{\cosh \left[\left(\frac{P_{C}}{P_{o}}\right)^{\beta}+\varepsilon\right]+\gamma}\right]
$$

where

$$
\begin{aligned}
& P_{O}, 0,1, \gamma, \beta \text { are parameters } \\
& 0 \text { is the moisture content } \\
& f \text { is the porosity of the soil }
\end{aligned}
$$

Data points and fitted moisture content curves by King (22) are shown in Figure 2 .

The Equations 5 and 6 were used in test simulations. However, during the tests two limitations of this approach were noted. First, solving Equations 5 and 6 and evaluating their complex derivatives is computationally slow. Second and more importantly, Equation 6 has the property that as $\mathrm{P}_{\mathrm{C}} \rightarrow \infty, \mathrm{S}$ approaches the limit

$$
\lim _{\mathrm{P}_{C} \rightarrow \infty}=\frac{\delta(\cosh \varepsilon-\gamma)}{(\cosh \varepsilon+\gamma)}
$$




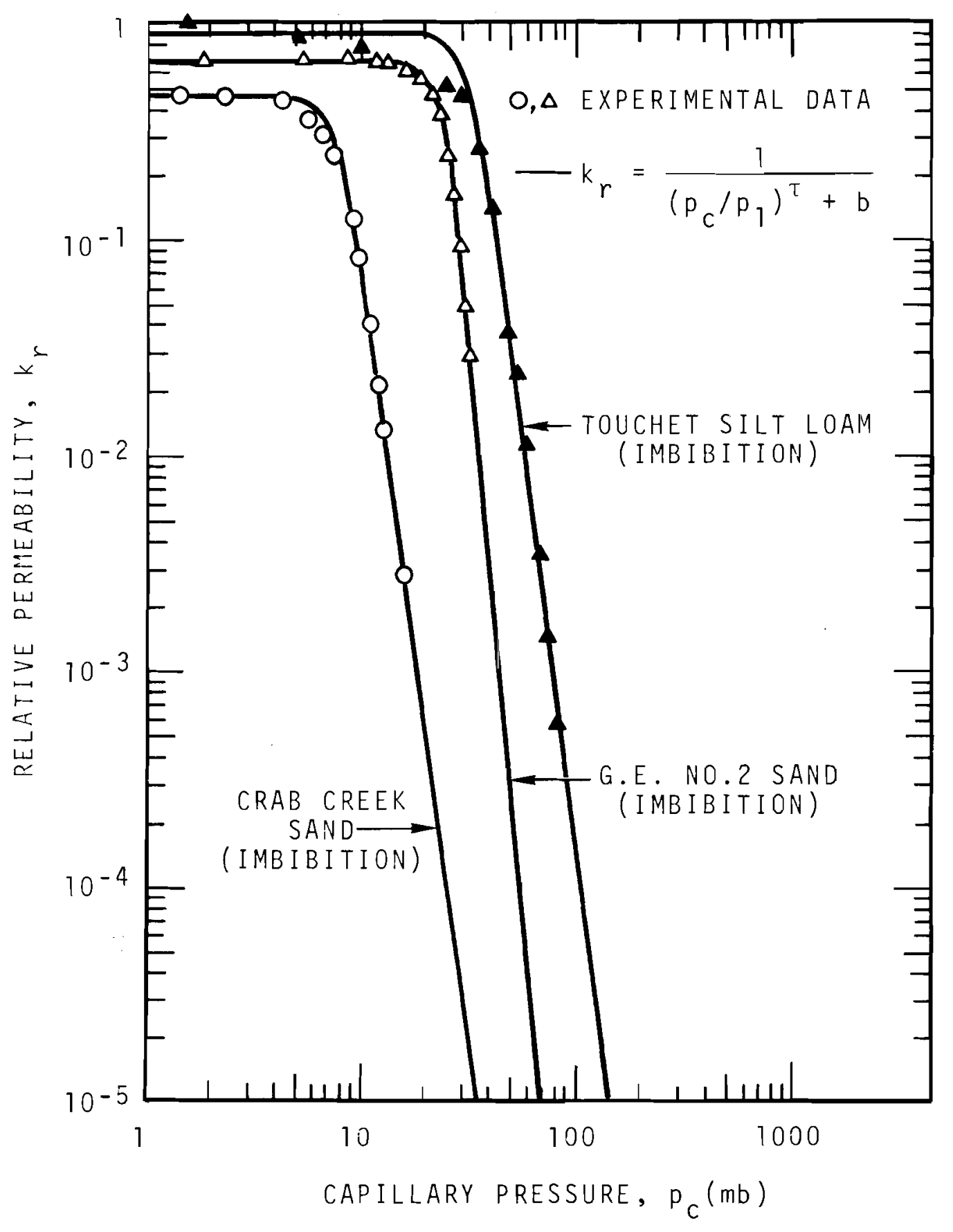

FIGURE 1. Relative Permeability Versus Capillary Pressure Curve and the Functional Fitting Equation 


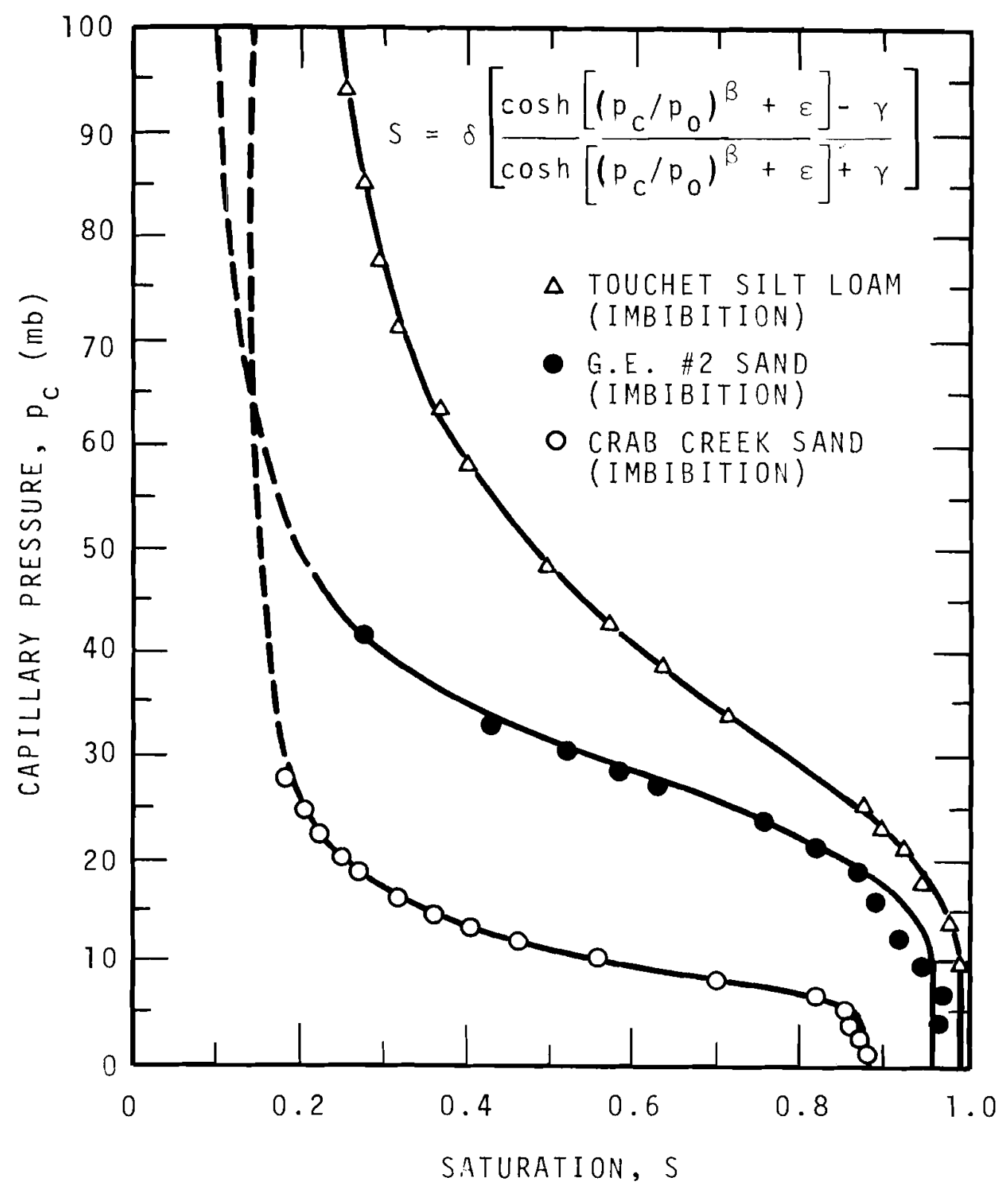

FIGURE 2. Capillary Pressure Versus Saturation Curves and the Functional Fitting Equation 
Thus the saturation has a limiting value which depends on the curve fit used and may be larger than the background moisture contents observed in the field. In addition, as the calculated moisture content approaches this limit, numerical instability can occur since slight changes in moisture content result in large changes in capillary pressure. Thus initial moisture contents have to be set at a level greater than the limit of $\mathrm{S}$ and the boundary conditions also must be set to maintain this minimum level of saturation in order to avoid these numerical instability problems.

In an attempt to circumvent these problems, two other fitting methods were tried. A computer program was written to solve the modified Millington and Quirk equation for computing the hydraulic conductivity curve for partially saturated soil from the moisture retention versus suction measurements and the saturated hydraulic conductivity $(19,21)$ However, several problems arose during application of this method. The limited suction data that are normally collected are inadequate to accurately describe the moisture retention curve. Thus, interpolation techniques were employed with which to generate a uniformly spaced set of data from the sparse, randomly spaced suction data. In generating the hydraulic conductivity curves from these data, two types of errors were introduced, measurement and interpolation, which caused small undulations to occur in the hydraulic conductivity curves. Figure 3 shows the moisture content curve; note the undulation from the curve fitting. Figure 4 shows the resulting hydraulic conductivity curve. In the PST Model the minor reversal of slopes along the curve of saturation versus capillary pressure curves caused difficulties with time plane convergence. This problem was solved by drawing a smooth curve through the generated moisture retention data and using very closely spaced data points.

A third method developed by Campbell (23) was adopted which bypasses these problems and requires less suction data than the Millington and Quirk method and also avoids the interpolation problems. The empirical expression suggested by Campbell (23) which relates water content to capillary pressure is:

$$
P_{c}=P_{e}\left(\frac{\theta}{\Theta_{s}}\right)^{-d}
$$




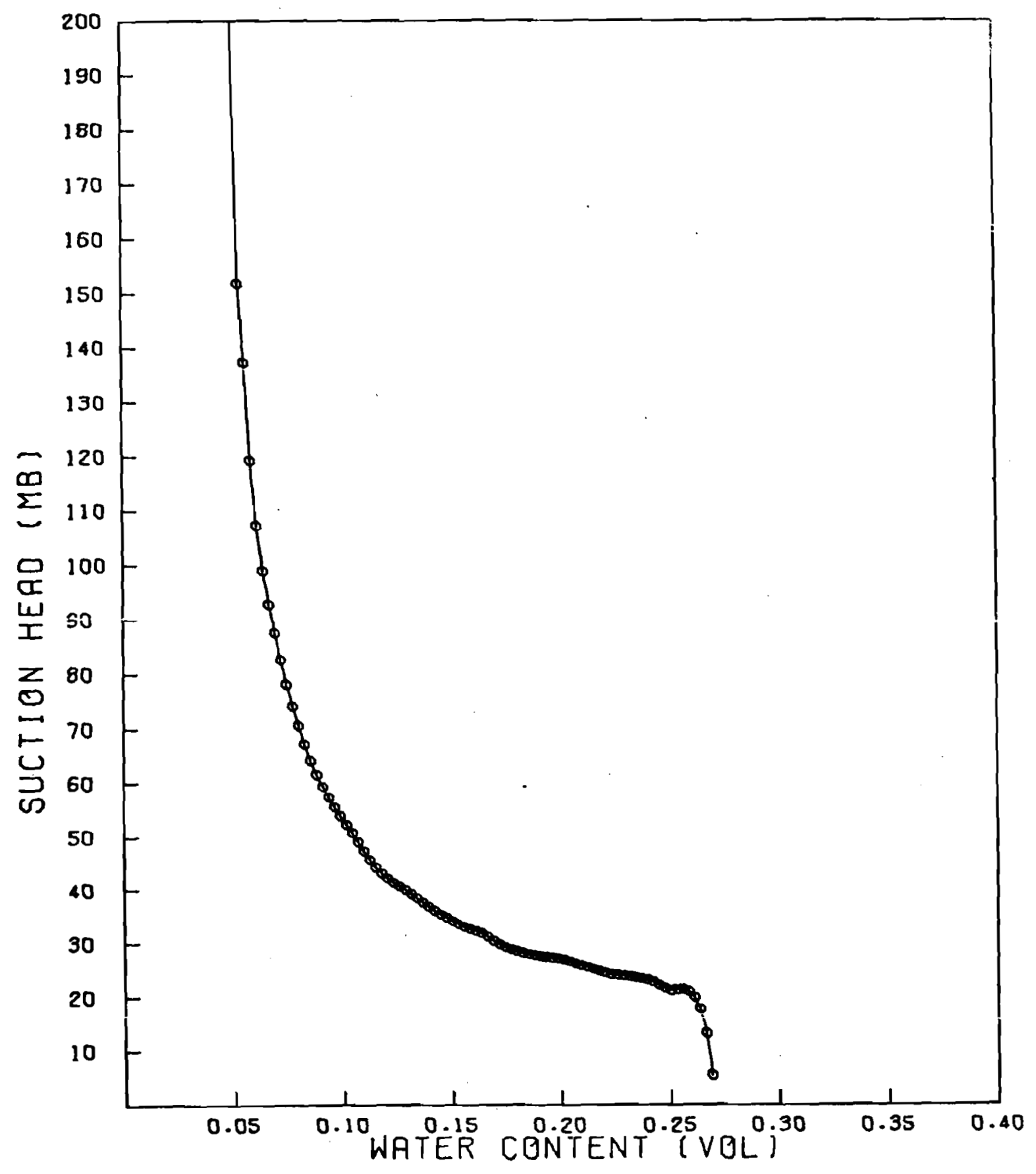

FIGURE 3. Water content Versus suction Head for the "A" Tank Farm Soil 


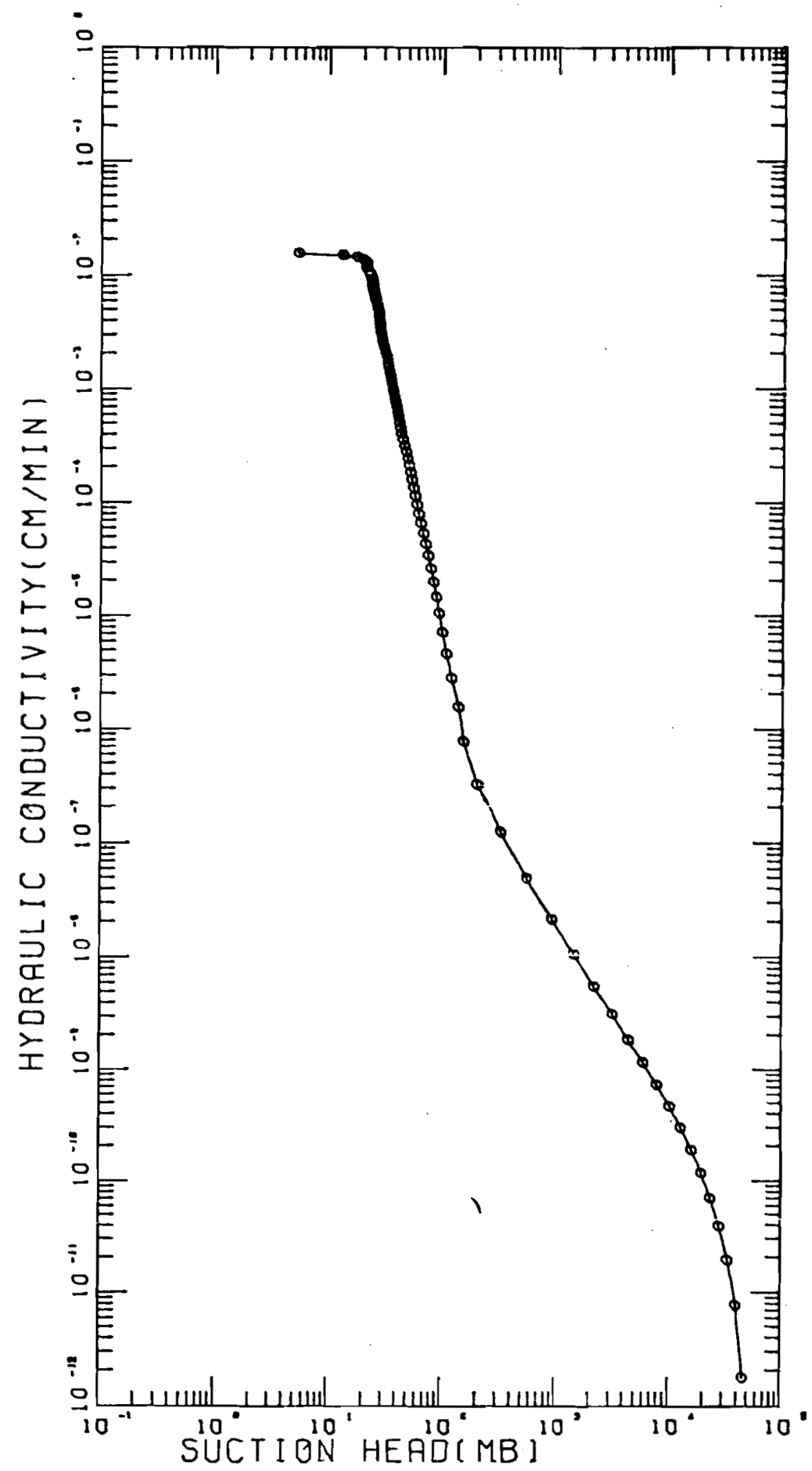

FIGURE 4. Hydraulic Conductivity Versus fsuction Head for the "A" Tank Farm Soil 
where $P$ is the air entry water pressure and $O$ is the saturatęd moisture content and $d$ is an empiricălly determined constant. The hydraulic conductivity function is also an empirical expression (2.3)

$$
K=K_{s}\left(\frac{P_{e}}{P_{c}}\right)^{2+\frac{3}{d}}
$$

where $K_{\text {}}$ is the saturated hydraulic conductivity. These equations do not have artificially high asymptotes as occur when using King's equations and are computationally more efficient. This method of handling these functional relationships is by far the best of the methods tested.

\section{FINITE DIFFERENCE EQUATIONS}

Several different methods for writing finite difference equations exist. The Crank-Nicolson method was selected because it is unconditionally stable and experimental tests using other techniques gave unsatisfactory results. Although Crank-Nicolson guarantees unconditional stability, it does not prevent instabilities from occurring. However, any instabilities that occur are bounded and will decay, rather than grow, with time. The method basically involves writing the equations at the mid-point of the time step; i.e., to approximate the derivatives three points in the old time plane and three points in the new time plane are used, as shown in Figure 5 .

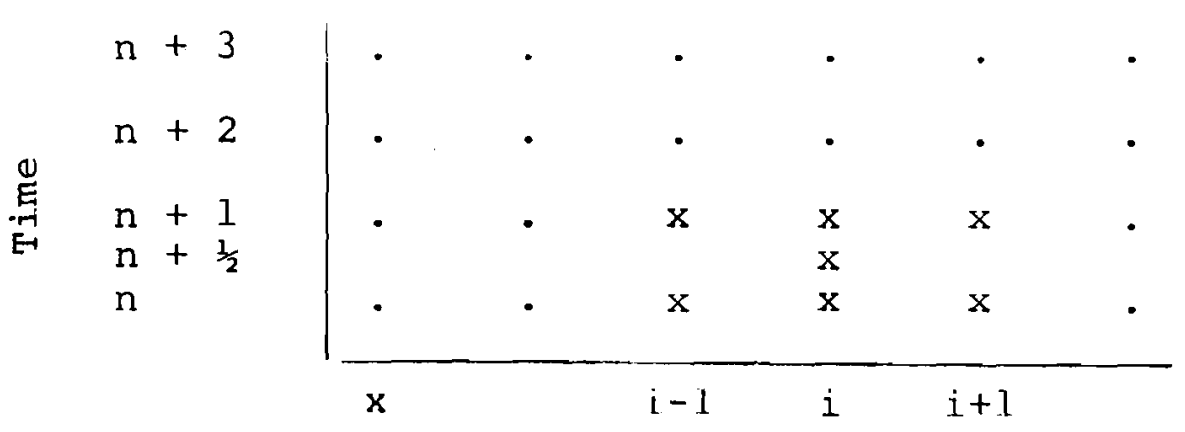

space

FIGURE 5. Points Used in Time and Space for Crank-Nicolson Finite Difference Expression 
Development of the finite difference form of Equation 2 using the Crank-Nicolson method is described in Appendix $B$. The resultant difference equation is

$$
\phi_{i, j}^{n+1}=\frac{L^{n+1}+L^{n}+2 \hat{r} N^{n+1 / 2} \phi_{i, j}^{n}-\phi_{i, j}^{n}\left(Q^{n}\right)+2 q}{2 \hat{r} N^{n+1 / 2}+Q^{n+1}}
$$

where

$$
\begin{aligned}
& L^{n+1}=K_{i+1 / 2, j}^{n+1} \phi_{i+1, j}^{n+1}+K_{i-1 / 2, j}^{n+1} \phi_{i-1, j}^{n+1} \\
& +k_{i, j+1 / 2}^{n+1} \phi_{i, j+1}^{n+1}+k_{i, j-1 / 2}^{n+1} \phi_{i, j-1}^{n+1} \\
& L^{n}=K_{i+1 / 2, j}^{n} \phi_{i+1, j}^{n}+K_{i-1 / 2, j}^{n} \phi_{i-1, j}^{n} \\
& +k_{i, j+1 / 2}^{n} \phi_{i, j+1}^{n}+k_{i, j-1 / 2}^{n} \phi_{i, j-1} \\
& Q^{n+1}=k_{i+1 / 2, j}^{n+1}+k_{i-1 / 2, j}^{n+1}+k_{i, j+1 / 2}^{n+1}+k_{i, j-1 / 2}^{n+1} \\
& Q^{n}=K_{i+1 / 2, j}^{n}+K_{1-1 / 2, j}^{n}+K_{i, j+1 / 2}^{n}+k_{i, j-1 / 2}^{n} \\
& \hat{r}=\frac{\Delta z \Delta x}{\Delta t} \\
& N^{n+1 / 2}=\left(\frac{\partial \theta}{\partial P_{C}}\right)^{n+1 / 2}=\frac{\left(\frac{\partial \theta}{\partial P_{C}}\right)^{n+1}+\left(\frac{\partial \theta}{\partial \bar{P}_{C}}\right)^{n}}{2} \\
& \Delta \mathbf{z}, \Delta \mathbf{x}=\text { vertical and horizontal grid spacing } \\
& \Delta t=\text { time increment } \\
& i, j=\text { grid point indices } \\
& \mathrm{n}=\text { time plane index }
\end{aligned}
$$


An algorithm similar to the Gauss-Seidel numerical solution method was used to solve Equation 9. Minimal effort was applied to optimizing the solution technique since the main objective was to achieve operational status of the model to determine if solutions for the types of problems and hydrogeologic conditions that prevail at the Hanford Reservation could be generated.

\section{BOUNDARY CONDITIONS}

The myriad of practical flow problems which may be modeled present three basic types of boundary conditions:

1) boundaries along which the potential, specified

$$
\phi=\text { constant, } t \geq 0
$$

2) boundaries across which no flow occurs

$$
\frac{\partial \phi}{\partial z}=0 \text { or } \frac{\partial \phi}{\partial x}=0, t \geq 0
$$

3) boundaries across which a known amount of flow ccours

$$
q=\text { constant, } t \geq 0
$$

Types 1 and 2 are the most common boundary conditions. Type 3, a typical example of which is the evaporation of water from a soil surface or a constant rainfall, may be modeled using a known flow rate or by a type 1 boundary if a proper potential can be determined. The type 2 boundary is normally used for describing impermeable boundaries.

\section{GENERAL PROGRAM DESCRIPTION}

The PST Model as developed handled a matrix of 6000 nodes, limited by computer storage. This capacity was increased by the computer capability to utilize partial computer words to conserve storage. Three pieces of information are packed into one memory location for each node in the problem: 1) an index for identifying the specific soil type for each node; 2) calculation type identification for the equation (internal or boundary) to be used at each node for calculating the potential; and 3) an index identifying the flux or input flow for each node. 
Even then the problem size had to be restricted because grid spacing beyond a few centimeters at the wetting front in the sediments caused more rapid advancement.

Equation 9 forms the basis for the PST flow program. Equation 9 represents only the general form of the basic equation; 24 no-flow boundary equations developed from various shapes of nodes (Figure 6) are available in the program.

Since a Gauss-Seidel type iterative scheme is used for solving the resultant matrix, the hydraulic potential is solved for in a point-by-point fashion, updating all of the stored data to its latest value immediately. In the computer program the information stored at each node includes the type of soil, the type of calculation, an index to a flux value table, the potentials from the present and past time planes, the hydraulic conductivity, and Crank-Nicolson term.

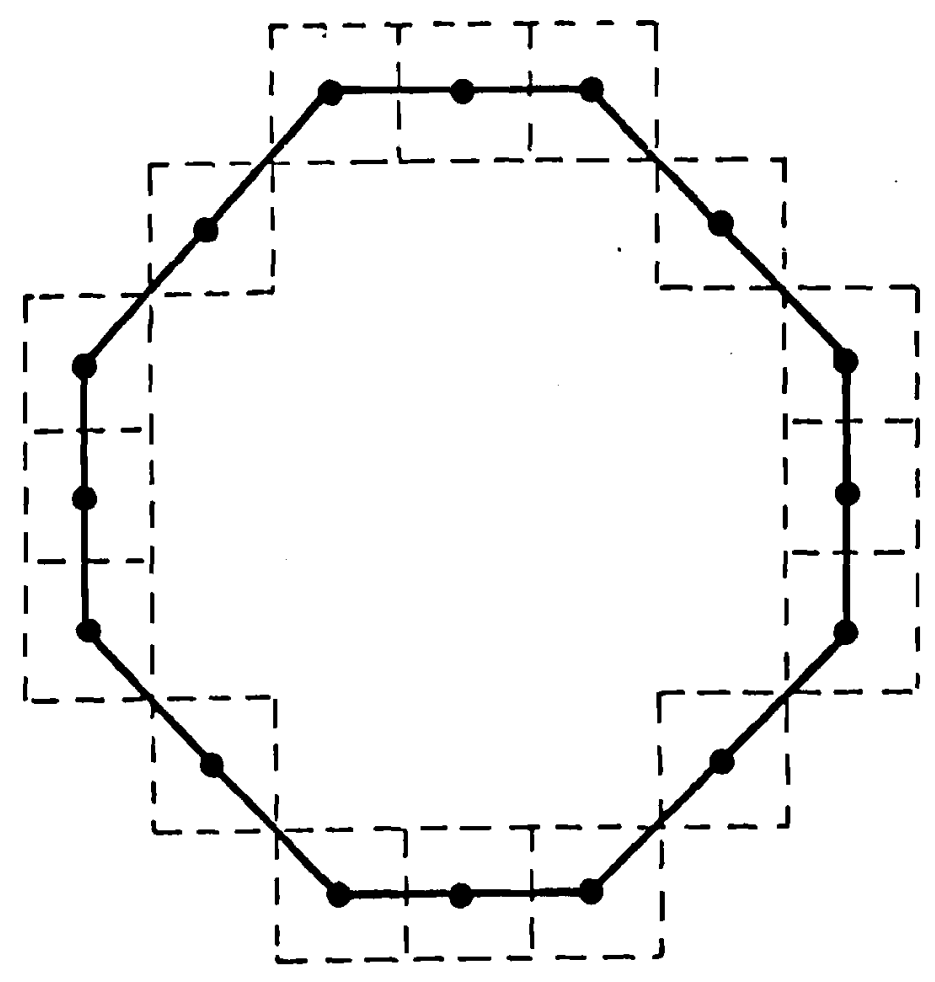

FIGURE 6. Schematic Showing Shapes and Rotation of Available Boundary Nodes 


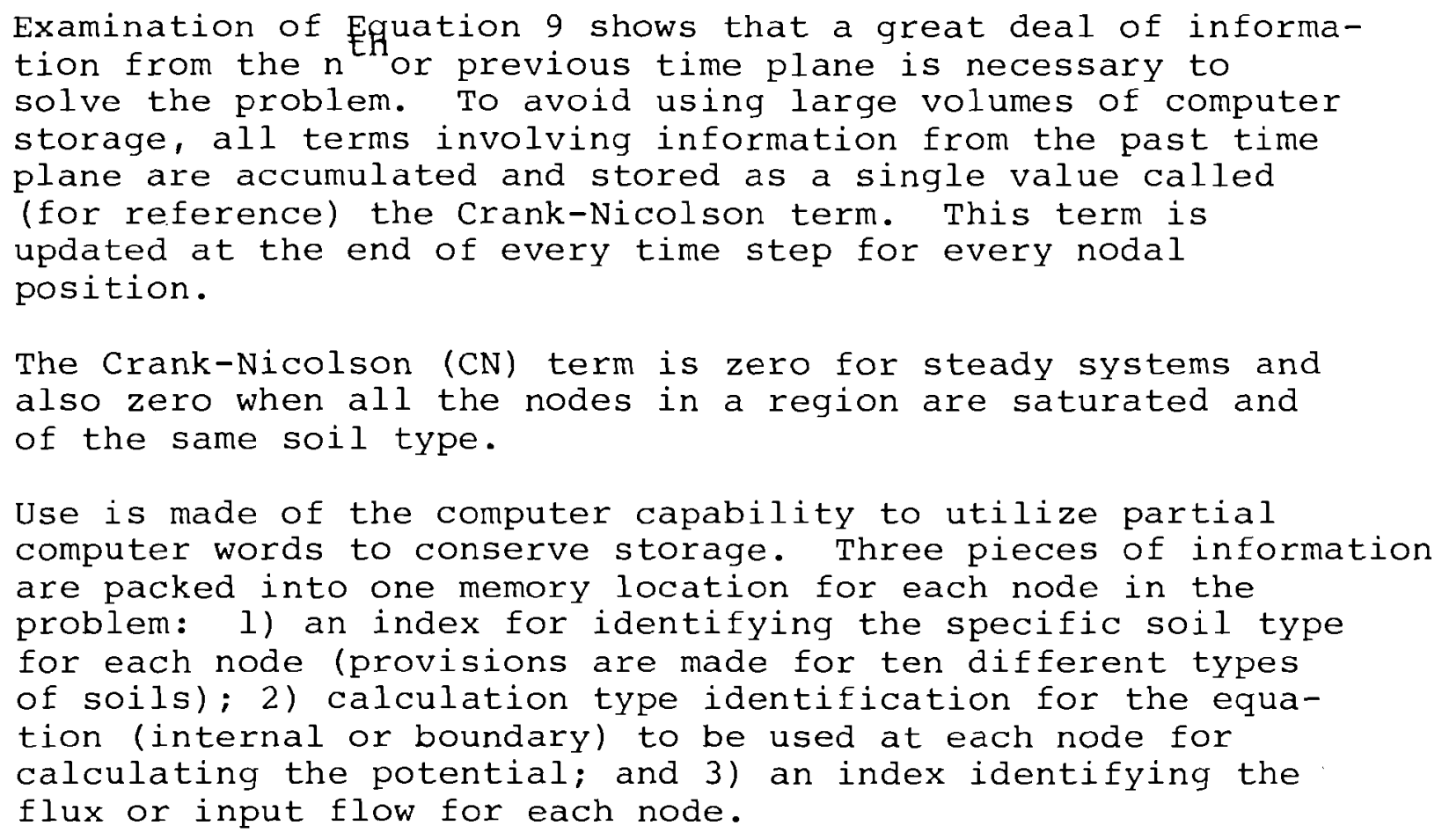




\section{REFERENCES}

1. Corey, A. T., "Flow in Porous Media, Course outline for AE-278 and AE-730." Dept. Agr. Eng., Colorado State University, Fort Collins, Colorado. 1969.

2. Richards, L. A., "Capillary Conduction of Liquids Through Porous Mediums." Phys., 1, 318-333. 1931.

3. Freeze, R. A., "The Mechanism of Natural Groundwater Recharge and Discharge, 1, One-Dimensional, Vertical, Unsteady, Unsaturated Flow Above a Recharging or Discharging Ground-Water Flow System." Water Resour. Res., 5(1), 153-171. 1969.

4. Rubin, J., "Theoretical Analysis of Two-Dimensional Transient Flow of water in Unsaturated and Partly Unsaturated Soils." Soil Sci. Amer. Proc. 32, 607-615. 1968 .

5. Hornberger, G. M., I. Remson, and A. A. Fungaroli, "Numeric Studies of a Composite Soil Moisture Groundwater System." Water Resour. Res., 5(4), 797-802. 1969.

6. Taylor, G. S. and J. N. Luthin, "Computer Methods for Analysis of Water-Table Aquifers." Water Resour. Res., 5(1), 144-152. 1969 .

7. Cooley, R. L., "A Finite Difference Method for Analyzing Liquid Flow in Variably Saturated Porous Media." Paper presented at the 5lst Annual AGU Meeting, Washington, D.C., April 20-24, 1970 .

8. Verma, R. D. and W. Brutsaert, "Unconfined Aquifer Seepage by Capillary Flow Theory." J. Hydraul. Div., Amer. Soc. Civil Eng., $96(11 Y 6), 1330-1344$. 1970.

9. Brutsaert, W., "Immiscible Multiphase Flow in Ground Water Hydrology: A Computer Analysis of the Well Flow Problem." Ph.D. thesis, Colorado State University, Fort Collins, Colorado. 1970.

10. Green, D. W., C. F. Weinaug, and Hassan Dabiri, "Numerical Modeling of Unsaturated Groundwater Flow." Contribution No. 31, Kansas Water Resources Research Institute, Manhattan, Kansas.

11. Freeze, A. R., "Three-Dimensional, Transient, SaturatedUnsaturated Flow in a Ground-Water Basin." Water Resources Research, Vol. 7, No. 2. April 1971. 
12. Taylor, S. A. and J. W. Cary, "Linear Equations for the Simultaneous Flow of Matter and Energy in a continuous Soil system." Soil Sci. Soc. Amcr. Proc. Vol. 28, 167-172.

13. Phillip, J. R. and D. A. DeVries, "Moisture Movement in Porous Materials Under Temperature Gradients." Transactions American Geophysical Union, 38 (2) 222-231. 1957.

14. Letey, J., W. D. Kemper, and L. Norman, "The Effect of Osmotic Pressure Gradients on Water Movement in Unsaturated Soil." Soil Sci. Soc. Amer. Proc. 33:15-18. 1969.

15. Gardner, Robert, "Some Soil Properties Related to Sodium Salt Problems in Irrigated Soils." Technical Bulletin No. 902 , USDA.

16. Richards, L. A., "Uptake and Retention of water by Soils as Determined by Distance to a water Table." Physics, Vol. $1,318-333$.

17. Dane, J. H. "Effects of Hysteresis on the Prediction of the Infiltration, Redistribution and Drainage of Water in a Large Soil Column." Thesis, Department of Agronomy New Mexico State University, 1972.

18. King, L. G., "Inhibition of Fluids by Porous Solids." Unpublished thesis, Colorado State University, Fort Collins, Colorado, December 1964.

19. Millington, R. J. and J. P. Quirk, "Permeability of Porous Solids." Trans. Faraday Soc. 57:1200-1207. 1961.

20. Jackson, R. C., R. J. Reginato, and C. H. M. van Bavel "Comparison of Measured and Calculated Hydraulic Conductivities of Unsaturated Soils." Water Resour. Res., $1: 375-380$. 1965 .

21. Reisenauer, A. E., "Calculation of Soil Hydraulic Conductivity from Soil-Water Retention Relationships." Battelle Pacific Northwest Laboratories, BNWL-1710, Richland, Washington. 1972 .

22. King, L. G., "Description of Soil Characteristics for Partially Saturated Flow." Soil Sci. Amer. Proc. 29 (4), 359-362. 1962 .

23. Campbel1, G. S., "A Simple Method for Determining Unsaturated Conductivity from Moisture Retention Data." Soil Science, Volume 117, No. 6, 1974. 


\section{ACKNOWLEDGMENTS}

The authors would like to thank Professor Gaylon Campbell for preparing Appendix $A$ and for his much appreciated advice and encouragement.

This research was sponsored by the Ground water Management Section, Research Department, Atlantic Richfield Hanford Company. The authors are grateful for the direction and review assistance of R. A. Arnett, Senior Hydrologist and Dr. R. A. Deju, Manager, Ground Water Management Section. 
APPENDIX A

\section{GENERALIZED EQUATIONS DESCRIBING HEAT AND MASS TRANSPORT IN UNSATURATED POROUS MEDIA}

Prepared by

Dr. G. S. Campbell

Washington State University 


\section{APPENDIX A}

DERIVATION OF MOISTURE FLUX EQUATIONS FOR UNSATURATED SOIL

Conservation of mass requires that for a given volume of soil:

$$
\frac{\partial \theta}{\partial t}=-\frac{\partial J_{W X}}{\partial x}-\frac{\partial J_{W Y}}{\partial y}-\frac{\partial J_{W Z}}{\partial z}+G(x, Y, z)=-\nabla \cdot J_{W}+G(x, Y, z)
$$

where $\theta$ is mass concentration of water, $t$ is time, $J_{W}$ is mass $f I u x$ of water, and $\mathrm{G}$ is the rate of water production (or negative consumption per unit volume of soil).

Water flux may result from gradients in matric potential, gravitational potential, osmotic potential, and temperature. One needs to consider fluxes in both the liquid and the vapor phase. Let us consider the flux in the $\mathrm{z}$ direction. Fluxes in other directions would be written in similar fashion but without the gravitational component. The theory of irreversible thermodynamics provides a general approach which is useful for this type of problem. ${ }^{3}$

The liquid-phase flux, denoted by superscript $\ell$, can be written as:

$$
\mathrm{J}_{\mathrm{w}}^{\ell}=-\mathrm{L}_{\mathrm{ww}}^{\ell} \mathrm{x}_{\mathrm{w}}-\mathrm{L}_{\mathrm{wq}}^{\ell} \mathrm{x}_{\mathrm{q}}-\mathrm{L}_{\mathrm{wS}}^{\ell} \mathrm{x}_{\mathrm{S}}
$$

and the vapor phase flux, denoted by superscript $v$, as:

$$
J_{w}^{v}=-L_{w w}^{v} x_{w}-L_{w q}^{v} x_{q}-L_{w s}^{v} x_{s}
$$

where the L's are transport coefficients, X's are driving forces, and $\mathrm{w}, \mathrm{q}$, and $\mathrm{s}$ denote water, heat, and salt. The total flux is the sum of the liquid and vapor phase fluxes.

If we write $\beta=\mathrm{L}_{W q} / \mathrm{L}_{\mathrm{WW}}$ and $\sigma=\mathrm{L}_{\mathrm{WS}} / \mathrm{L}_{\mathrm{WW}}$ ! where $\beta$ is the heat of transport and $\sigma$ is the reflection coefticient, Equations 2 and 3 become:

$$
\begin{aligned}
J_{w}=J_{w}^{l}+J_{w}^{v}= & -L_{w w}^{l}\left(x_{w}+\beta^{l} X_{C_{I}}+\sigma^{l} X_{S}\right) \\
& -L_{w w}^{v}\left(x_{w}+\beta^{v} x_{q}+\sigma{ }^{v} x_{S}\right)
\end{aligned}
$$

The coefficients and forces must now be chosen to be dimensionally consistent. The liquid transport coefficient, $L_{W W}^{l}$, is just the hydraulic conductivity, $k(\theta)$, and the driving force for water flow is the sum of the gravitational and matric potential gradients:

$$
\mathrm{X}_{\mathrm{W}}=\left.\frac{\partial \Psi_{\mathrm{m}}}{\partial \mathrm{Z}}\right|_{\mathbf{T}}+\frac{\partial \Psi_{\mathrm{g}}}{\partial \mathbf{z}}
$$


Since the matric potential, $\Psi_{m}$, may vary with temperature it is necessary to specify that the gradient be taken at constant temperature.

The other driving forces are:

$$
\begin{aligned}
& x_{q}=\frac{1}{T} \frac{\partial T}{\partial Z} \\
& x_{s}=\frac{\partial \Psi_{0}}{\partial z}
\end{aligned}
$$

Where $T$ is the Kelvin temperature and $\Psi_{0}$ is the osmotic potential. with this choice of driving forces:

$$
\beta^{l}=T \frac{\partial \Psi_{m}}{\partial T}
$$

The reflection coefficient, $\sigma^{l}$, is just a fraction giving the effectiveness of osmotic potential gradients in causing flow compared to the effectiveness of matric gradients.

If we define the vapor phase driving forces the same as those for liquid-phase flux, then the coefficients must take up the conversion from vapor concentration to potential since the driving force for vapor movement is a gradient in vapor concentration.

To find $\mathrm{L}_{\mathrm{Ww}}^{v}$, we can write for isothermal vapor diffusion:

$$
J_{W}^{v}=-\left.D_{v} \frac{\partial \rho_{v}}{\partial z}\right|_{T}=-\left.\left.D_{v} \frac{\partial \rho_{v}}{\partial \Psi}\right|_{T} \frac{\partial \Psi}{\partial z}\right|_{T}
$$

where $D_{v}$ is the vapor diffusivity in soil, $\rho_{v}$ is the vapor density, and $\Psi$ is the sum of the matric, osmotic, and gravitational potentials. The osmotic component can be included with the others because $\sigma^{v}=1$. From equation 5 the transport coefficient for vapor is:

$$
L_{W W}^{v}=\left.D_{v} \frac{\partial \rho_{v}}{\partial \Psi}\right|_{T}
$$

The relationship between water potential and vapor density is:

$$
\rho_{v}=\rho_{v}^{\circ} \exp \left(\frac{\Psi}{\mathrm{RT}}\right)
$$

where $\rho_{\nu}^{\circ}$ is the saturation vapor density and $R$ is the specific gas constant for water. In the normal range of water potentials encountered in soil water flow problems, $\Psi / R T<<1$ and Equation 7 becomes:

$$
\rho_{v}=\rho_{v}^{0} \exp (\Psi / \mathrm{RT}) \approx \rho^{0}\left(1+\frac{\Psi}{\mathrm{RT}}\right)
$$


and from Equation 6:

$$
L_{w W}^{v}=\frac{D_{v} \rho_{v}^{0}}{R T}
$$

The vapor flux resulting from temperature gradients can be expressed as:

$$
\mathrm{J}_{\mathrm{w}}^{v}=-\mathrm{D}_{v} \frac{\partial \rho_{v}}{\partial \mathbf{z}}=-\mathrm{D}_{v} \frac{\partial \rho_{v}}{\partial \mathrm{T}} \frac{\partial \mathrm{T}}{\partial \mathbf{z}}
$$

The driving force for thermally induced flow is $\frac{1}{T} \frac{\partial T}{\partial z}$ so from Equation 4 and Equation 8 :

$$
\mathrm{J}_{\mathrm{w}}^{U}=-\frac{\mathrm{L}_{\mathrm{w}} \mathrm{w}^{\beta}}{\mathrm{T}} \frac{\partial \mathrm{T}}{\partial \mathbf{z}}=-\frac{\mathrm{D}_{v^{\rho} v^{\circ}}^{\beta}}{\mathrm{RT}^{2}} \frac{\partial \mathrm{T}}{\partial \mathbf{z}}
$$

Equating 9 and 10 and solving for $\beta$ gives:

$$
\beta=\frac{R T^{2}}{\rho \dot{O}} \frac{\partial \rho_{v}}{\partial \mathrm{T}}
$$

The claussius-Clapeyron equation can be used to find $\frac{\partial \rho}{\partial T}$. It gives:

$$
\frac{\partial \rho}{\partial T}=\frac{\rho v^{\lambda}}{R T^{2}}
$$

Where $\lambda$ is the latent heat of vaporization, combining this with Equation 11 gives:

$$
\beta=\lambda,
$$

a result confirmed experimentally by Taylor and Cary (1964). ${ }^{3}$

Equation 4 can now be rewritten incorporating the explicit forms of the coefficients and forces giving:

$$
\begin{aligned}
\mathrm{J}_{\mathbf{W}}= & -\left[\mathbf{k}(\theta)+\frac{\mathrm{D}_{v^{\rho} v}^{0}}{\mathrm{RT}}\right]\left[\left(\frac{\partial \Psi_{\mathrm{m}}}{\partial \mathbf{z}}\right)_{\mathbf{T}}+\frac{\partial \Psi_{\mathbf{g}}}{\partial \mathbf{z}}\right] \\
& -\left[\sigma \mathbf{k}(\theta)+\frac{\mathrm{D}_{v} \rho_{v}^{0}}{\mathrm{RT}}\right]\left(\frac{\partial \Psi_{0}}{\partial \mathbf{z}}\right)_{\mathrm{T}}-\left[\mathbf{k}(\theta) \frac{\partial \Psi_{\mathrm{m}}}{\partial \mathrm{T}}+\frac{\mathrm{D}_{v} \rho_{v}^{\circ} \lambda}{\mathrm{RT}^{2}}\right] \frac{\partial \mathrm{T}}{\partial \mathbf{z}}
\end{aligned}
$$

When temperature and salt concentration gradients are absent, the second and third terms in Equation 12 are zero. When significant transport does occur from these driving forces, the simultaneous transport of water, heat, and salt must be accounted for. The flux equations are:

$$
J_{s}=-L_{s s} X_{s}-L_{s w} x_{w}-I_{s q} X_{q}
$$




$$
J_{q}=-L_{q q} x_{q}-L_{q w} x_{w}-I_{q s} x_{s}
$$

These would be used with mass and energy conservation equations to describe temperature, salt concentration, and water content as function of position and time in the soil. If the salts are ionic, a fourth equation must be added to describe flow of electricity. One sees quickly that a complete solution to this problem would be impossibly difficult. Fortunately, considerable simplification can be achieved by considering the sizes of various terms. Both $\mathrm{k}(\theta)$ and $\mathrm{D}_{v} \rho_{v}^{O}$ are functions of water content, since $D_{v}$ depends on air-filled pôrosity of the soil. Philip and DeVries ${ }^{4}$ give:

$$
D_{v}=D_{0} v a a
$$

where $D_{0}$ is the diffusion coefficient for water vapor in air, $v$ is an "enhancement factor" to account for diffusion in excess of that predicted by simole theory, $\alpha$ is a tortuosity factor to account for the tortuous diffusion path and a is air filled porosity. We will take $\alpha=0.66$ and $\nu=4$ as typical of unsaturated soil. The air filled porosity; $a$, is:

$$
\mathrm{a}=1-\frac{\mathrm{b}}{\mathrm{p}}-\frac{\mathrm{o}_{\mathrm{b}}}{\mathrm{P}_{\mathrm{w}}}
$$

where $\rho_{\mathrm{b}}=$ bulk density, $\rho_{\mathrm{p}}=$ particle density, and $\rho_{\mathrm{w}}$ is the density of liquid water. Taking $\rho_{b} / \rho_{p}=0.5$ and $\rho_{b} / \rho_{w}=1.3$ gives:

$$
\mathrm{a}=0.5-1.3 \theta
$$

and

$$
\mathrm{D}_{v}=\mathrm{D}_{\mathrm{o}}(1.3-3.4 \theta)
$$

At $20 \mathrm{C}, D_{O}=0.24 \mathrm{~cm}^{2} \mathrm{sec}^{-1}, \rho_{v}^{0}=17.3 \times 10^{-6} \mathrm{~g} \mathrm{~cm}$

$$
\mathrm{R}=4.6 \mathrm{Bar} \mathrm{K}^{-1} \text {, and } \mathrm{T}=293^{\circ} \mathrm{K} \text {. }
$$

$$
\frac{\mathrm{D}_{v} \rho_{v}^{0}}{\mathrm{RT}}=3 \times 10^{-9}(1.3-3.4 \theta) \mathrm{g} \mathrm{Bar}^{-1} \mathrm{sec}^{-1} \mathrm{~cm}^{-1}
$$

Hydraulic conductivity as a function of water content, can be written as (Campbell, 1974):

$$
k(\theta)=k_{s}\left(\frac{\theta}{\theta_{s}}\right) d
$$

where $k_{\mathbf{s}}$ and $\theta_{\mathbf{s}}$ are hydraulic conductivity and water content at saturation, and $\mathrm{d}$ is an empirical constant. Values of $\mathrm{k}, \theta_{\mathrm{s}}$, and d will vary of course from soil to soil, but for the moment we will assume typical values of $\theta_{s}=0.38, k_{s}=1.0 \mathrm{~g}$ Bar $-\frac{1}{1} \sec ^{-1} \mathrm{~cm}^{-1}$ and $d=10$. The liquid and vapor conductivity are compared in the following table: 


\section{TABLE 1. Liquid and Vapor Conductivity at Relative Moisture Contents for Typical Sandy Soil}

\begin{tabular}{lcc}
$\frac{\theta}{\theta_{S}}$ & $k(\theta)$ & $\frac{D_{v} \rho_{v}^{0}}{R T}$ \\
0.2 & $10^{-7}$ & $3.0 \times 10^{-9}$ \\
0.4 & $10^{-4}$ & $2.3 \times 10^{-9}$ \\
0.6 & $6 \times 10^{-3}$ & $1.6 \times 10^{-9}$ \\
0.8 & 0.1 & $0.8 \times 10^{-9}$ \\
1.0 & 1.0 & \multicolumn{2}{c}{0}
\end{tabular}

Obviously, vapor transport is of little concern in isothermal flow problems.

The reflection coefficient, $\sigma$, has been measured under conditions which tend to maximize its value (sodium saturated, fine textured soil) by Letey, et.al. $(1969)^{1}$. They found $\sigma<0.04$ for'soils wetter than 0.5 Bar. Values might be expected to be even smaller for coarse textured, low salt soils. Since $\frac{\partial \Psi_{0}}{\partial z}$ is probably not greater than $\frac{\partial \Psi}{\partial z}+\frac{\partial \Psi}{\partial z}$, osmotically induced flow would normally be, at most, a few percent of the total. This is negligible compared to other uncertainties, so the entire second term of Equation 12 can generally be neglected.

Taylor and Stewart $(1960)^{2}$ give data which can be used to find $\frac{\partial \Psi_{m}}{\partial T}$. From their data we obtain approximately:

$$
\frac{\partial \Psi_{\mathrm{m}}}{\partial \mathrm{T}}=0.02 \Psi_{\mathrm{m}}
$$

Typically, $\Psi_{\mathrm{m}}$ is a few tenths of a bar in flow problems, therefore:

$$
\frac{\partial \Psi_{m}}{\partial T}=0.005
$$

is a commonly accepted value. Using numbers from Table 1 , at $\frac{\theta}{\theta_{s}}=0.2$,

$$
k(\theta) \frac{\partial \Psi_{m}}{\partial T}=5 \times 10^{-10}
$$

and, with $\lambda / \mathrm{T}=24330 / 293=83 \mathrm{Bar} / \mathrm{k}$,

$$
\frac{\mathrm{D}_{\nu}{ }^{\circ}{ }_{\nu} \lambda}{\mathrm{RT}^{2}}=2.6 \times 10^{-7}
$$


Thermally induced liquid flow is obviously unimportant at this water content, but the vapor term would have a significant contribution anytime $\frac{\partial T}{\partial z}$ became of similar magnitude to $\frac{\partial \Psi_{m}}{\partial z}+\frac{\partial \Psi^{\prime}}{\partial z}$. The gravitational gradient is $10^{-3} \mathrm{Bar} / \mathrm{cm}$, so temperature gradients as large as $10^{-3} \mathrm{~K} / \mathrm{cm}$ might cause significant flow in soils with $\theta / \theta_{s}=0.2$ or drier. In wetter soil $k(\theta)$ becomes much larger while the thermal term becomes smaller, and the thermally induced flow can generally be neglected.

With these simplifications, Equation 12 finally reduces to the flow equation which is normally used.

$$
J_{w}=-k(\theta) \frac{\partial \Phi}{\partial z}
$$

where $\Phi=\psi_{\mathrm{g}}+\psi_{\mathrm{m}}$. In three dimensions:

$$
\overline{\mathrm{J}}_{\mathrm{W}}=-\mathbf{k}(\theta) \nabla \Phi
$$

The transient equation (Equation 1) becomes:

$$
\frac{\partial \theta}{\partial t}=-\nabla \cdot \bar{J}+G(x, y, z)=\nabla \cdot[k(\theta) \nabla \Phi]+G(x, y, z)
$$

Except where root extraction of water by plants occurs, $G(x, y, z)=0$. 


\section{REFERENCES}

1. J. Letey, W. D. Kemper and L. Noonan, "The Effect of Osmotic Pressure Gradients on Water Movement in Unsaturated Soil," Soil Science Society of America Proceedings, 33:15-18, 1969.

2. S. A. Taylor and G. L. Stewart, "Some Thermodynamic Properties of Soil Water," Soil Science Society of America Proceedings, $24: 243-247$, 1960 .

3. S. A. Taylor and J. W. Cary, "Linear Equations for the Simultaneous Flow of Matter and Energy in a Continuous Soil System," Soil Science Society of America Proceedings, 28:167-172, 1964 .

4. J. R. Philip and D. A. DeVries, "Moisture Movement in Porous Materials Under Temperature Gradients," Trans. Am. Geophys. Union, 38:222-232, 1957 . 
APPENDIX B

DEVELOPMENT OF FINITE-DIFFERENCE EQUATIONS 


\section{APPENDIX B}

The development of the finite-difference approximation to the partial differential equation is of some interest because this technique can be used systematically to develop equations for no-flow boundary nodes for a great variety of shapes by integration of the flow around the elemental block.

Equation 1 in the text may be written as

$$
\underline{\nabla} \cdot(K \underline{\nabla} \phi)+q=\frac{\partial \theta}{\partial t}
$$

where $q$ has been added to define a source or sink term with a node.

Now consider Equation 1 in a region $\mathrm{R}$ and at each node point $(i, j)$, construct a region $r_{i, j}$ within $R$ such that

$$
0=\iint_{r_{i, j}}\left(\underline{\nabla} \cdot(\underline{K} \underline{\nabla} \phi)-\frac{\partial \theta}{\partial t}\right) d x d z
$$

Using Green's theorem to convert the first part of Equation 2 to a line integral

$$
\iint_{r_{i, j}} \partial \frac{(K \underline{\nabla} \phi)}{\partial x} i_{i}-\left(-\partial \frac{(K \underline{\nabla} \phi)}{\partial z}\right)_{j}=\oint_{\Gamma} \underline{i, j} \underline{\nabla} \phi \cdot \hat{n} \partial c
$$

where $\hat{\mathrm{n}}$ is the outward pointing normal vector and $\mathrm{dc}^{2}=\mathrm{dx}^{2}$ $+\mathrm{dz}^{2}$, $\Gamma_{i}{ }_{\mathrm{j}}$ is the boundary of $r_{i}, j$ and arc length $s$ increases Equation 2 then becomes

$$
\oint_{\Gamma_{i, j}} \underline{\nabla} \phi \cdot \hat{n} d c-\int_{r_{i, j}}\left(\frac{\partial \theta}{\partial t}\right) d x d z=0
$$

Consider the region $r_{i, j}$ as shown in Figure $B-1$. 


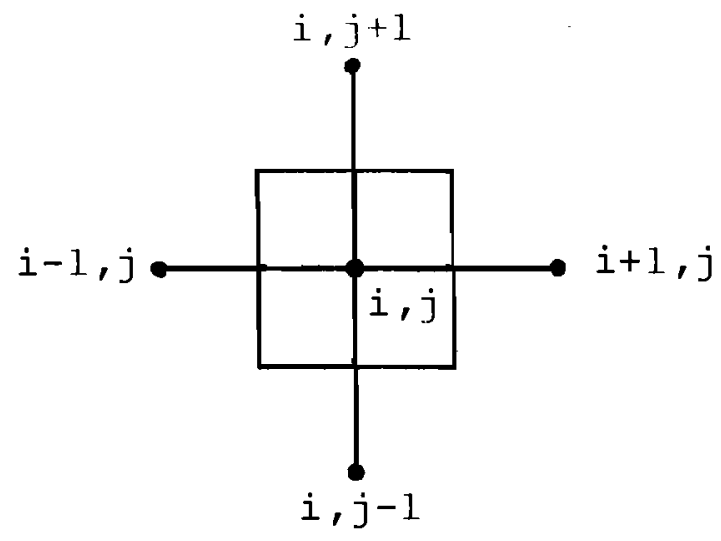

FIGURF B-1. Basic Node Net for Development of Difference Equations

The corner points of the node area are at $(i-1 / 2, j-1 / 2)$, $(i+1 / 2, j-1 / 2),(i+1 / 2, j+1 / 2)$, and $(i-1 / 2, j+1 / 2)$. We can then write

$$
a_{i, j}=d x d z=\Delta x \Delta z
$$

Integrating the equation for the region, $r_{i, j}$ gives

$$
\begin{aligned}
& \int_{z j+1 / 2}^{z} k\left(x_{i-1 / 2,}^{j-1 / 2}\right) \phi_{x}\left(x_{i-1 / 2, z)} d z=\Delta z k_{i-1 / 2, j}\left(\frac{\phi^{n}{ }_{i, j}{ }^{-\phi^{n}} i-1, j}{\Delta x}\right)_{(6)}\right.
\end{aligned}
$$

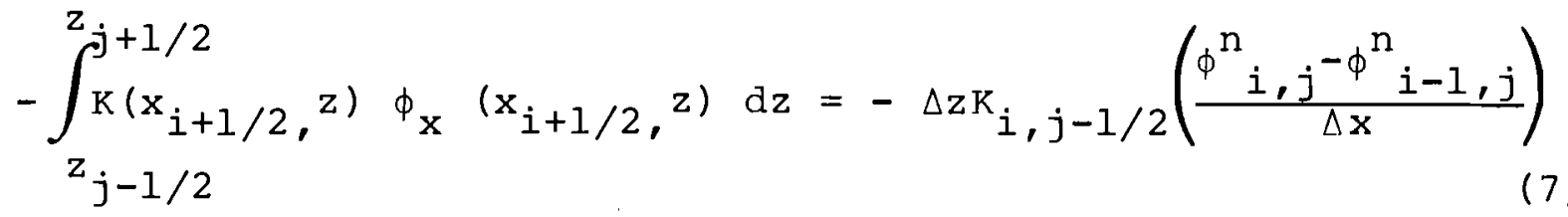

$$
\begin{aligned}
& \int_{i-1 / 2}^{i+1 / 2} K\left(x, z_{j-1 / 2}\right) \phi_{z}\left(x, z_{j-1 / 2}\right) d x=\Delta x k_{i+1 / 2, j}\left(\frac{\phi_{i+1, j}^{n}-\phi^{n} i, j}{\Delta z}\right)
\end{aligned}
$$




$$
\begin{aligned}
& -\int_{i+1 / 2}^{i-1 / 2} k\left(x, z_{j+1 / 2}\right) \phi_{z}(x, z j+1 / 2) d x=\Delta x k_{i, j+1 / 2}\left(\frac{\phi_{i, j+1}^{n}-\phi^{n} i, j}{\Delta z}\right) \\
& \int_{\Gamma_{i, j}} k \frac{\partial \phi}{\partial \hat{n}} d c=0 \\
& \int_{i, j}\left(\frac{\partial \theta}{\partial t}\right) d x d z=\left(\frac{\theta^{n+1} i^{-\theta^{n}} i, j}{\Delta t^{n}}\right) \Delta x \Delta z \\
& \int_{r} q d x d z=q \Delta x \Delta z
\end{aligned}
$$

From the above, the basic finite-difference equation is written as:

$$
L_{1}(K, \phi)+L_{2}(K, \phi)-M(\theta)-\phi_{i, j}\left(Q_{1}(K)+Q_{2}(K)\right)+\bar{q}=0
$$

$$
\begin{aligned}
& \text { where } L_{1}(K, \phi)=K_{i+1 / 2, j} \phi_{i+1}+K_{i-1 / 2, j} \phi_{i-1} \\
& L_{2}(K, \phi)=K_{i, j+1 / 2} \phi_{i, j+1}+K_{i, j-1 / 2} \phi_{i, j-1} \\
& \frac{\theta_{i, j}^{n+1}-\theta_{i, j}^{n}}{\Delta t} \\
& Q_{1}(K)=K_{i+1 / 2, j}+K_{i-1 / 2, j} \\
& Q_{2}(K)=k_{i, j+1 / 2}+K_{i, j-1 / 2} \\
& \overline{\mathrm{q}} \quad \mathrm{q} \Delta \mathrm{x} \Delta \mathrm{z}
\end{aligned}
$$

If we assume the boundary of the region to pass through the elemental node, as in Figure $\mathrm{B}-2$ with the shaded area internal to the flow regime, we can perform the foregoing integration and determine the boundary equation. The result is similar to Equation 12:

$$
\begin{gathered}
1 / 2 I_{1}(K, \phi)+K_{i, j-1 / 2} \phi_{i, j-1} \\
-M(\theta)-\left\{1 / 2 Q_{1}+K_{i, j-1 / 2}\right\}_{i, j}+\bar{q}=0 \\
B-3
\end{gathered}
$$




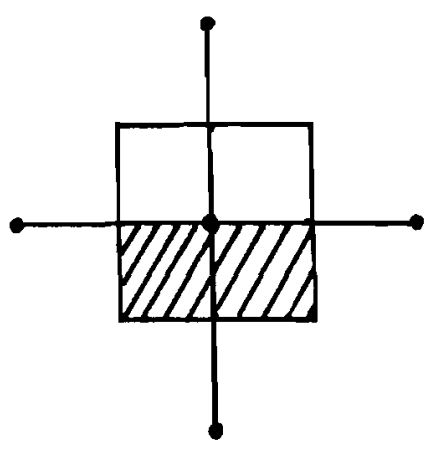

FIGURE B-2. Boundary Node for No-flow

between Bottom and Top of Node

Note that the $j+1$ terms are not included. This results in a boundary node through which no flow may pass in the $y$ direction or the flow is parallel to the boundary.

Through the same process, a series of boundary node equations describing no-flow boundaries were developed for the shapes of the partial nodes that fit the perimeter of an octagon. Figure A-3 shows the shapes and their various rotations where the heavy line represents the no flow side of each nodal area.

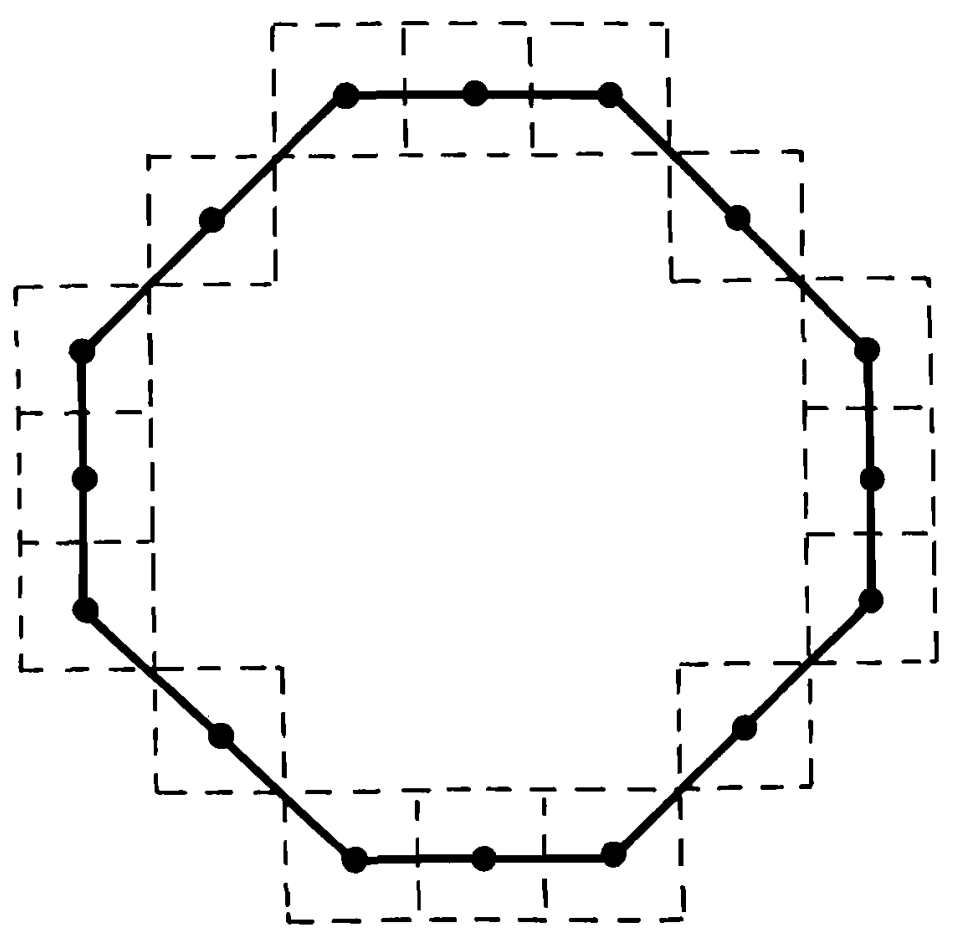

FIGURE B-3. Schematic Showing Shapes and Rotation of Available Boundary Nodes

The utilization of these nodes prevent small right angle corner stagnation areas which hinder convergence in the analyses. 
DISTRIBUTION

No. of Copies

1

215

2

2
Off-Site

Chicago Patent Group

A. A. Churm

Energy Research and Development Administration Technical Information Center

Energy Research and Development Administration Headquarters

Waste Management and Transportation Division

Germantown, Maryland 20767

Owen P. Gormley

Chief, Waste Facilities Branch

Robert W. Ramsey, Jr.

Chief, Development Branch

Nuclear Regulatory Commission

Directorate of Regulation

7920 Norfolk Avenue

Bethesda, Maryland 20014

Ronald L. Bullard

Chief, Environmental Specialist Branch

W. Gamill

Chief, Site Analysis Branch

Energy Research and Development Administration Division of Production \& Material Management Washington, D. C. 20545

William L. Lennemann

Chief, Chemical Process

James W. Pollock

Energy Research and Development Administration Idaho Falls, Idaho 83401

Dr. Adrian H. Dahl

Chief, Environmental Science Branch

B. L. Schmalz

$$
\text { Distr-1 }
$$




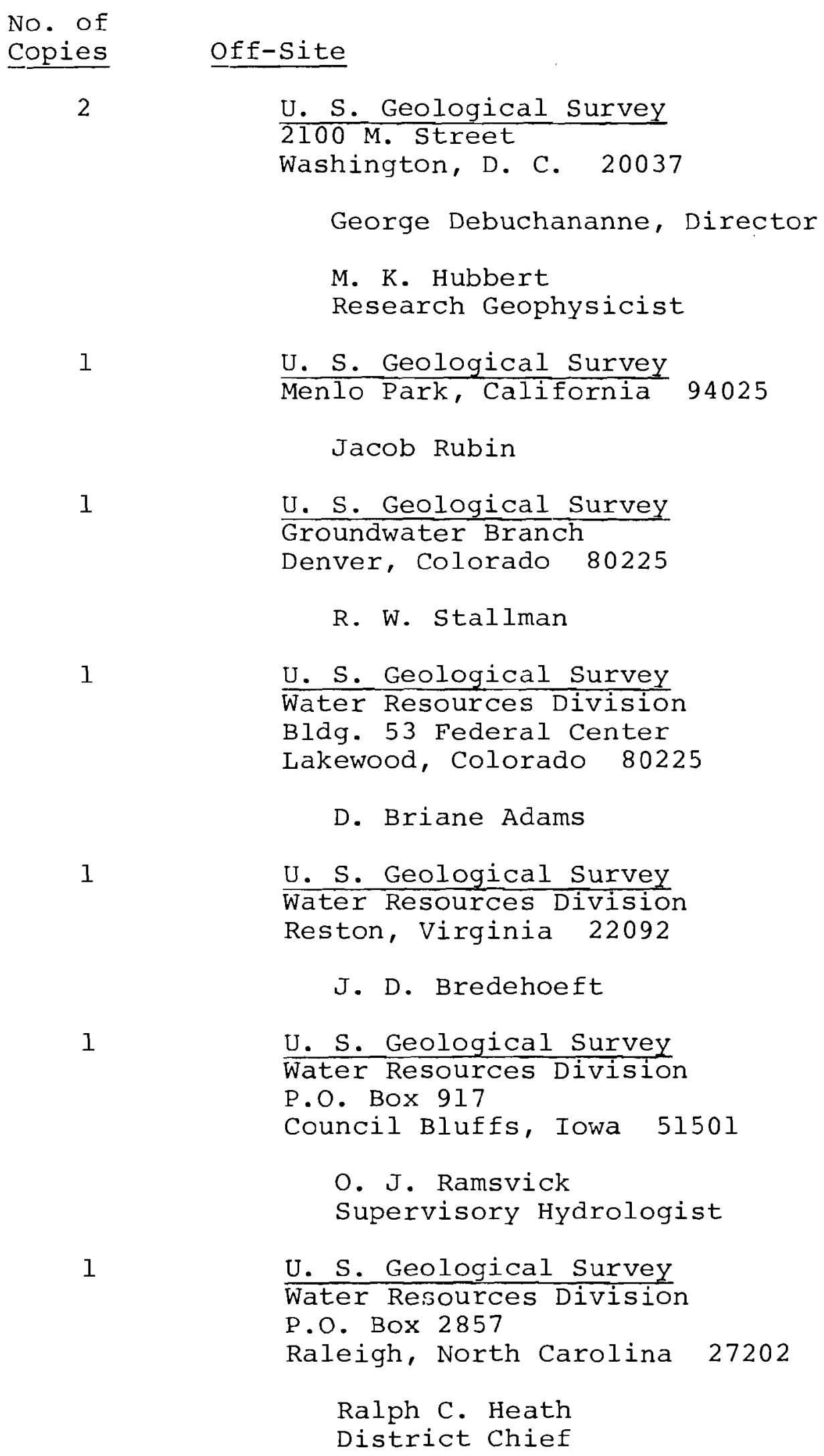

U. S. Geological Survey 
No. of

Copies

2

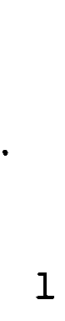

1

1

1

1

1

1
off-Site

U. S. Bureau of Mines

Spokane Mining Research Laboratory

N. 1430 Washington st.

Spokane, Washington 99201

Robert C. Bates

Michael M. McDonald

Environmental Protection Agency

Crystal Mall

Washington, D. C. 20460

Arnold Joseph

Environmental Protection Agency

Office of Research \& Monitoring

Edison water Quality office

Edison, New Jersey 08817

Richard Field

National Water Commission

800 N. Quincy

Arlington, Virginia 22209

Dr. John S. Gladwell

USDA-ARS

Engineering Research Center

CSU Foothills Campus

Fort Collins, Colorado 80521

Dr. David A. Woolhiser

Hydraulic Engineer

USDA-ARS

P.O. BOX 1096

Boise, Idaho 83701

J. L. Robins

USDA-ARS

Snake River Conservation Research Center Route 1, Box 186

Kimberly, Idaho 83341

Dr. Marvin E. Jensen, Director

$$
\text { Distr-3 }
$$


No. of

Copies

Off-Site

1

USDA Hydrograph Laboratory

Plant Industry station

Soils Building

Beltsville, Maryland 20705

H. N. Holton, Director

1

USDA Sedimentation Laboratory

P.O. BOX 30

Oxford, Mississippi 38655

A. R. Robinson, Director

1

USDA-ARS

North Central Watershed Research Center

P.O. Box 916

Columbia, Missouri 65201

Dr. C. R. Amerman

Hydraulic Engineer

1

USDA-ARS

Northeast Watershed Research Center

Pensylvania State University

111 Research Building 3

University Park, Pennsylvania 16802

Dr. A. S. Rogowski

Soil Scientist

1

National Academy of Science

U. S. National Committee for the IHD 2101 Constitution Avenue

Washington, D. C. 20418

Dr. Leo Heindl

Executive Secretary

National Academy of Science

Committee on Radioactive Waste Management National Research Council

2101 Constitution Avenue

Washington, D. C. 20418

Dr. Cyrus Klingsberg

Technical Secretary 
No. of

Copies

Off-Site

1

National Science Foundation

Division of Advanced Technology Application 1800 Sixth Street N.W.

Washington, D. C. 20530

Ray Zahradnik

1

Robert S. Kerr Water Research Center P.O. Box 1198

Ada, Oklahoma 74820

Dr. J. W. Keeley

1

Alabama Geologic Survey

P.O. Box Drawer 0

University, Alabama 35486

Phil Lammereaux

State Geologist

1

Idaho Bureau of Mines \& Geology

University of Idaho

Moscow, Idaho 83843

Dr. Roy E. Williams

1

Idaho Department of Water Administration

State House, Annex 2

Boise, Idaho 83707

Keith R. Higginson, Director

1

Idaho water Resources Board

Boise, Idaho

R. R. Lee

1

Illinois state Water Survey

P.O. Box 232

Urbana, Illinois 61801

Keros Cartwright 
No. of

Copies

1

1

1

1

1

1

1
Off-Site

State of Maine

Environmental Improvement Commission

Augusta, Maine 04330

Steven D. Freedman

St. Anthony Falls Hydraulic Laboratory Mississippi River at Third Avenue East Minneapolis, Minnesota 55414

Professor C. Edward Bowers

Desert Research Institute

Center for water Resources Research

Reno, Nevada

Dr. Clinton Case

State of North Carolina

Groundwater Division

Water and Air Resources

Raleigh, North Carolina 27611

Harry M. Peek, Chief

Water Quality Management Laboratory

Rt. 2, Box 322A

Durant, Oklahoma 74701

V. L. Hauser

State of oregon

516 Public Service Bldg.

Salem, Oregon 97310

Chris Wheeler

State Engineer

State of Washington

Department of Ecology

Olympia, Washington 98504

Eugene F. Wallace 
No. of

Copies

Off-Site

1

Washington State Water Research Center

Pullman, Washington 99163

James Crosby, III

Geologist

1

Atomic Industrial Forum, Inc.

475 Park Avenue South

New York, New York 10016

Gerald V. Halvorsen

Environmental Projects Manager

1

Boeing Computer Services

Federal Building

Richland, Washington 99352

R. W. Nelson

1

Sandia Laboratories

Division $5 \overline{166}$

Albuquerque, New Mexico 87115

1

University of Arizona

Office of Arid Lands Studies

1201 East Speedway Blvd.

Tucson, Arizona 95719

Dr. Ken Faster

1

University of Arizona

Department of Hydrology and Water Resources 200-E Old Psychology

Tucson, Arizona 95721

Dr. A. K. Tyagi

1

University of Arizona

Tucson, Arizona 95721

E. S. Simpson 
No. of

Copies

Off-site

2

University of California

Berkeley, California 94720

Dr. Warren Kauffman

P. A. Witherspoon

Department of Civil Engineering

1

University of California at Davis Department of water Sciences and Engineering Davis, California 95616

J. N. Luthin

University of California at Riverside College of Biological \& Agricultural Sciences Riverside, California 92507

Dr. N. T. Coleman

1

Stanford University

Department of Civil Engineering

Stanford, California 94305

Paul Kruger

1

Stanford University

School of Earth Sciences

Department of Ecology

stanford, California 94305

E. Aguado

1

Georgia Institute of Technology

School of Civil Engineering

Atlanta, Georgia 30332

Dr. J. R. Wallace

2

University of Illinois

Urbana, Illinois 61801

A. Klute

Professor Ven Te Chow

Hydrosystems Laboratories

Distr-8 
No. of

Copies

Off-Site

1

Iowa State University

Ames, Iowa

D. Kirkham

1

Massachusetts Institute of Technology 77 Massachusetts Avenue Room 48-263

Cambridge, Massachusetts 02139

Dr. Donald Harleman

1

University of Minnesota

Department of Civil Engineering

Minneapolis, Minnesota 55418

H. Steforn

2

University of Nebraska School of Civil Engineering

Lincoln, Nebraska 68503

Mark J. Hammer

Warren Viessman, Jr.

1

Princeton University

School of Engineering/Applied Science

Department of Civil and Geological

Engineering

Princeton, New Jersey 08540

Dr. Robert W. Cleary

Princeton University

Department of Civil and Geological

Engineering

Princeton, New Jersey 08540

R. J. M. DeWiest

G. F. Pinder

Distr-9 
No. of

Copies

Off-Site

New Mexico State University

Department of Agronomy

P. O. Box $3 Q$

Las Cruces, New Mexico 88001

P. J. Wierenga

1

New Mexico Institute of Mining and Technology Department of Geosciences

Socorro, New Mexico 87801

Lynn W. Gelhar

1

State University of New York at Buffalo

Department of Mechanical Engineering

Buffalo, New York 14214

Ralph T. Cheng

1

State University of New York at Buffalo

Department of Civil Engineering

Buffalo, New York 14214

Dr. Ralph Rumer

1

Cornell University

School of Civil Engineering

B22 Bailey Hall

Ithaca, New York 14850

W. H. Brutsaert

1

Oregon State University

Corvallis, Oregon 97331

Dr. Larry Boersma

Professor of Soils

1

Drexel Institute of Technology

Philadelphia, Pennsylvania 19104

Irwin Remson

1

Vanderbilt university

Nashville, Tennessee 37203

Dr. Frank L. Parker

Distr -10 
No. of

Copies

Off-site

1

Utah State University

Utah water Research Laboratory

College of Engineering

Logan, Utah 84321

J. Paul Riley

1

University of Wyoming

Laramie, Wyoming 92070

Dr. Paul A. Rechard

Director, Water Resources Research

1

Washington State University

Department of Civil Engineering

148 sloan Hall

Pullman, Washington 99163

Dr. Donald L. Bender

2

Washington State University

Department of Agronomy and Soils

Pullman, Washington 99163

Dr. Walter H. Gardner

Dr. Gaylon S. Campbell

1

Washington State University

Albrook Hydraulic Laboratory

Pullman, Washington 99163

Dr. John F. Orsborn, Head

1

Washington State University

Agricultural Engineering Department

Pullman, Washington 99163

Dr. L. G. King

1

University of Wisconsin

Department of Soil Science

Madison, Wisconsin 53706

W. R. Gardner

Distr-11 
No. of

Copies

1

Off-Site

University of New South Wales

School of Civil Engineering

Sydney, Australia

Dr. K. K. Watson

1

McMaster University

Department of Civil Engineering

Hamilton, Ontario, Canada

Dr. William James

1

Institut de Mecanique (I.M.G.)

Domaine Universitaire

B. P. 53

Centre de Tri 38041

Grenoble-Cedex, France

Georges Vachaud

1

Technion-Israel Institute of Technology Haifa, Israel

J. Bear

1

AERE Harwell

Oxfordshire, England

Dr. K. L. Kipp

On-Site Hanford

9

ERDA Richland Operations Office

O. J. Elgert

J. L. Rhoades

P. J. Holsted

E. B. Jackson

P. G. Rhoades

R. B. Goranson

B. J. Melton

G. J. Bracken 
No. of

30

1

53

1

On-Site Hanford

Atlantic Richfield Hanford Co.

R. C. Arnett (10)

H. Babad

D. J. Brown

R. A. Deju

F. R. Dornheim

P. A. Eddy (10)

R. E. Gephart

R. E. Isaacson

R. K. Ledgerwood

M. W. Legatski

W. H. Riggsbee

H. P. Shaw

Westinghouse Hanford Co. HEDL

R. B. Hall

Battelle-Northwest

D. B. Cearlock

J. R. Eliason

A. E. Reisenauer

(20)

R. J. Serne

D. R. Friedrichs

S. W. Ahlstrom

R. G. Baca

C. R. Cole (10)

A. Brandstetter

R. W. Wallace

J. J. Fuquay

G. W. Dawson

Tech. Information

Tech. Pubs.

United Nuclear, Inc.

A. L. Cucchiara

Distr-13 